\title{
Água de beber, água de benzer: mito e rito na espiritualidade Potiguara
}

\section{Raquel de Lourdes de Miranda e Silva Carmona ${ }^{1}$, João Carlos de Miranda e Silva ${ }^{2}$, Cícero Sousa Lacerda ${ }^{3}$, Érika Marques de Almeida Lima ${ }^{3}$, Josemary M. Freire Rodrigues de C. Rocha ${ }^{3}$, Patrícia Tavares de Lima $^{3}$, Hercílio de Medeiros Sousa ${ }^{3}$, Luciano Honório de Carvalho $^{3}$ e Natália Marques de Almeida Lima Miranda $^{4}$}

\footnotetext{
${ }^{1}$ Universidade Federal da Paraíba. Programa de Pós-Graduação em Ciências das Religiões - PPGCR. Centro de Educação. Universidade Federal da Paraíba. Campus I. João Pessoa-PB, Brasil (CEP 58051-900). E-mail: carmona.miranda@gmail.com.

${ }^{2}$ Superintendência de Administração de Meio Ambiente - SUDEMA. Av. Monsenhor Walfredo Leal, 181. Tambiá. João Pessoa-PB, Brasil (CEP 58020-540).

${ }^{3}$ Instituto de Ensino Superior da Paraíba - IESP. Estrada de Cabedelo, BR 230, km 14, s/n. Morada Nova. Cabedelo-PB, Brasil (CEP 58109-303).

${ }^{4}$ Instituto do Patrimônio Histórico e Artístico da Paraíba - IPHAEP. Av. João Machado, 348. Jaguaribe. João Pessoa-PB, Brasil (CEP 58013-520).
}

Resumo. Este estudo mostra a importância da água para a espiritualidade indígena e, neste contexto, a essencialidade do sentido preservacionista que é despertado, seja pela questão dos saberes tradicionais que a tornam fonte vital, ou ainda, pela questão econômica e social que emoldura a sobrevivência das tradições dos Potiguara, evidenciando a água como elemento da cosmogonia indígena. Para tal, foi traçada uma breve trajetória sócio-histórica e antropológica que trouxe a fala Potiguara para apresentar o seu discurso a respeito de ancestralidade, meio ambiente, preservação e espiritualidade, por meio de uma pesquisa qualitativa e bibliográfica multidisciplinar que traz à superfície um dos mitos de origens mais sensíveis a esse povo indígena.

Palavras-chave: Saberes tradicionais; Cosmogonia Potiguara; Água; Espiritualidade indígena.

Abstract. Water to drink, water to bless: Myth and rite on Potiguara spirituality. This study shows the importance of water for indigenous spirituality and in this context, the essentiality of the preservationist sense that is awakened, either by the question of folk knowledge that make it a vital source, or by the economic and social question that frames the survival of traditions. Potiguara, highlighting the water as an element of indigenous cosmogony. For this, a brief socio-historical and anthropological trajectory was drawn that brought the Potiguara
Recebido:

$23 / 07 / 2019$

Aceito:

$30 / 08 / 2019$

Disponível on line:

$31 / 08 / 2019$

Publicado:

$31 / 08 / 2019$

Acesso aberto

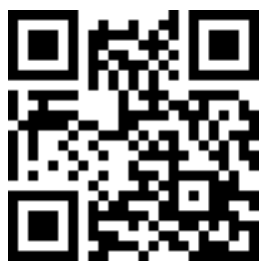

ORCiD

(D) 0000-0002-7192-3297 Raquel de Lourdes de Miranda e Silva Carmona 
perspective to present his discourse on ancestry, environment, preservation and spirituality, through a multidisciplinary qualitative and bibliographical research that brings to the surface one of the most sensible origins myth to this indigenous people.

Keywords: Folk knowledge; Indigenous spirituality; Potiguara cosmogony; Water.

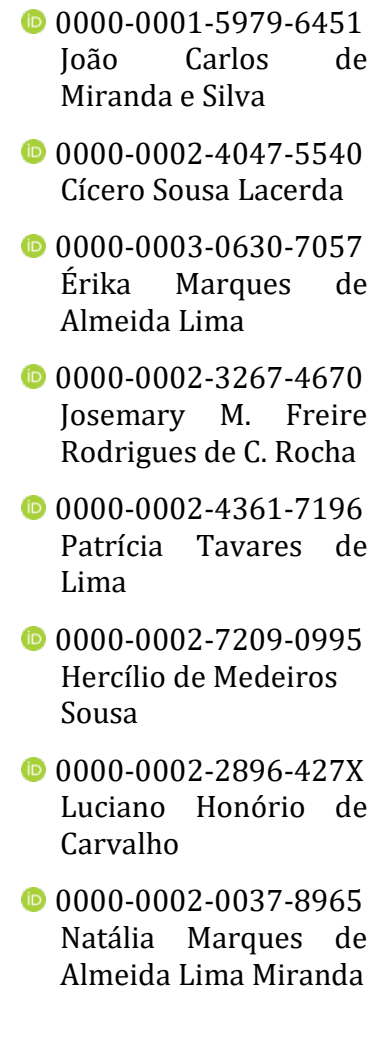

\section{Introdução}

A água é considerada um bem essencial para todas os povos. Desde as civilizações hidráulicas (Egito, e o Rio Nilo; Mesopotâmia, e os Rios Tigre e Eufrates, dentre outras), deve-se assinalar a sua essencialidade como elemento vital, que está nas necessidades básicas do homem e no seu modo de produção. Figura na história são somente como um bem material, ou patrimônio natural de suma importância, como também faz parte de um conjunto significativo, simbólico e fenomenológico envolvente, que lhe confere uma alma mística. Estudiosos das mais diversas ciências, de campos disciplinares distintos, como Freud (1856-1939), Bachelard (1884-1962) e Jung (18751961) dentre outros, produziram obras nas quais a água está associada ao conjunto de arquétipos presentes no inconsciente do homem (Silva, 2017), compondo um tecido multidisciplinar.

0 que se pretende neste artigo é apontar para o envolvimento entre o povo Potiguara e a água como um mito de origem, delineando o mito cosmogônico, ou seja, aquele mito que acrescenta, reinventa e continua se ressignificando (Eliade, 1972), que remete ao nascimento de tudo e todas as coisas. Enquanto bem material e patrimônio natural, a água está presente no território que abrange a área Potiguara em abundância, tanto em sua parcela de mar, quanto de rio e é com esse elemento, que o Potiguara estabelece uma relação mágica, associada ao sobrenatural, que faz parte de um conjunto mítico/místico.

Sua presença é considerada uma grande riqueza, como assinala Barcellos (2012), chamando a atenção que os indígenas Potiguara da Paraíba estão incluídos, imprimem nesse relacionamento a dualidade que transita, de maneira tênue, entre o material e espiritual. Portanto, apresentamos nesse artigo, que mostra a discussão entre autores que apresentam convergências nos seus discursos relativos ao tema de espiritualidade e etnicidade, dentre eles, 
Boff (1993) e Barcellos (2012) e, nesse viés questões como mito, rito e sacralidade com Campbell (1990), Vilhena (2005) e Eliade (1972;1992), são discutidas tecendo um diálogo de aproximação

A importância do olhar estrangeiro sobre o tema abordado, vem do documento escrito sob a pena vigilante do governador holandês. Uma fonte primária que mostra o seu ponto de vista comercial e estratégico, que em seu último ano de governo escreveu a Descrição Geral da Capitania da Parahyba (1639) (Herckmans, 1886). Outras contribuições como Moura Filha (2010) e Miranda e Silva (2017), que tratam da conquista da Paraíba e da crise hídrica no estado, foram importantes para esta construção.

\section{Da água que bebemos, nós nascemos}

Para início de conversa, seguimos o caminho apontados por Barcelos (2015), que mostra como é vivenciada a religiosidade do indígena Potiguara, mostrando como essa etnia (re)vive seus mitos, destacando as suas práticas rituais, que mesclam saberes tradicionais, elementos da herança ancestral e a prática religiosa predominantemente católica. Embora, o nosso foco seja a água como elemento de espiritualidade indígena, vale a referência ao contexto religioso, essencialmente por lembrar que apesar de serem conceitos intrínsecos não significam a mesma coisa.

É pertinente que aqui se dedique uma (ainda que pequena, portanto injusta) parte para mostrar o trabalho etnográfico desenvolvido, e do "agente histórico" delineado na obra de Barcellos.

Não apenas o objeto de estudo, alvo do pesquisador referenciado na introdução do trabalho como norte, rumo e prumo desse artigo, há ainda uma questão que pessoalmente "corre nas veias paraibanas" que é o pertencimento. 0 autor segue desmistificando a ideia de que índio-antropologia e antropólogo andam juntos. 0 que não significa dizer que a antropologia é desnecessária para a pesquisa etnográfica, antes pelo contrário, sua importância será ainda mais acentuada nas associações da transdisciplinaridade (Barcellos, 2012). É essa visão que entusiasma. Traz resultados muito mais próximos da realidade vivida, porque é a realidade vivenciada e que aproxima cada vez mais a academia do seu objeto, em uma relação dialética de práxis, por conceder também a aproximação do objeto com a academia, criando uma dinâmica de troca de saberes. Então é a vez de Clifford Geertz, Roberto Cardoso de Oliveira, Carlos Rodrigues Brandão e Alba Zaluar. Aqui já se vislumbra o olhar diferenciado para uma antropologia da religião. Para falar de história foi chamar o coração da Ècole des Analles, o historiador Marc Bloch, também mais recentemente, Michel de Certeau, Jacques Le Goff e Peter Burke. A teologia de Leonardo Boff e Frei Betto dialogam com a religiosidade que o autor imprimiu no seu discurso.

Enquanto metodologia a nossa proposta vai ao encontro da revisão bibliográfica, se debruçando na leitura de Barcellos (2012), sob a ótica delineada nas outras tantas leituras que faz dos autores, usando aqui a lógica da família passarinho que alimenta seus bebês com algo parcialmente digerido pela mamãe pássaro. E aqui as leituras são compreendidas como práxis, nas quais foram associadas a vivência e o discurso.

\section{Mãe Terra}

Água fecundada no ventre da

A luta pela terra tem custado muito cara ao povo Potiguara. Já no século XVII, o governador holandês da Companhia das índias Ocidentais, chamava a atenção para três aspectos fundamentais no litoral norte da capitania: a boa (bastante) povoação Potiguara, a abundância da água e a fertilidade da terra, com as suas palavras: “[...] Em águas, ares e fertilidade é esta Capitania uma das regiões mais 
saudáveis do Brasil, e em todos os tempos tem sido populosa e bem povoada pelos naturais da terra, chamados Pitiguares" (Herckmans, 1886, p. 239, grifo nosso). Ou ainda:

Todo território é rico em manancial de água doce, como muitas nascentes espalhadas ao longo dos vales, nas grotas, nos planaltos formando dezenas de fontainhas (parte molhada entorno de um olho d'água) que jorram de verão a verão, sem nenhuma vegetação ao redor. Ao longo do curso d'água são encontrados os tabuleiros, os paús (terrenos alagados), as camboas e os manguezais, formando uma vasta biodiversidade vegetal e animal de um rico ecossistema tropical (Barcellos, 2012, p. 87).

Apesar dos anos que separam os relatos de 1639 de Herckmans (1886) e Barcellos (2012), ambos exaltam as qualidades do patrimônio natural presentes nas terras dos Potiguara, e, portanto, só reforçam a ideia de que tais riquezas foram e continuam sendo atrativas ao explorador.

A efetiva conquista da terra e a supremacia do poder colonial só seria possível com o domínio do território, o que implicava na edificação das cidades, cuja construção requer a aplicação de matérias primas, as mais diversas, as quais permitem concretizá-la ao longo de séculos, associando-a à história do homem (Moura Filha, 2010). O colonizador pretendia retirar o índio da sua terra e a terra do índio, e hoje em dia, apesar de todos os esforços empreendidos e das conquistas alcançadas no que diz respeito ao processo de demarcação da área indígena, apenas a primeira vontade tenha se realizado. Ainda assim suas terras e suas águas continuam atraindo inimigos representantes da especulação imobiliária, usineiros e até algumas lideranças que em detrimento do coletivo, buscam interesses pessoais.
A água é um recurso renovável, mas não ilimitado como muitos podem pensar. Antes pelo contrário, a ação do homem e o seu relacionamento com o meio ambiente, além da má gestão dos recursos hídricos, tem colocado o planeta em risco. 0 índio sabe disso, o índio percebe isso, e ele entende justamente por que a sua relação com o meio ambiente está além da satisfação material, além do seu modo de fazer, está na verdade ligada ao seu modo de ser.

E dito assim, é sabido que a água é um dos principais elementos do imaginário cosmogônico indígena, e vem da sua ancestralidade. Como diz Boff (2006) referindo-se à espiritualidade oriental, que segundo ele, se apresenta destituída de dogmas, e só assim ouso comparar com a vivência do índio em sua relação com a água, ou seja, é vivendo plenamente essa ligação que ele se sente parte do universo como um todo, se sente planta, água, pedra, animal etc.

Não se pode desconhecer a importância do mito na vida cotidiana das aldeias. Há todo um mundo mágico, um universo do imaginário envolvente e transcendente, que se apresenta nos relatos míticos. Acerca do que há de simbólico na água:

A emersão repete 0 gesto cosmogônico da manifestação formal; a imersão equivale a uma dissolução das formas. É por isso que o simbolismo das Águas implica tanto a morte como o renascimento. O contato com a água comporta sempre uma regeneração: por um lado, porque a dissolução é seguida de um "novo nascimento"; por outro lado, porque a imersão fertiliza e multiplica o potencial da vida. À cosmogonia aquática correspondem, ao nível antropológico, as hilogenias: a crença segundo a qual o gênero humano nasceu das Águas (Eliade, 1992, p. 65).

Também no imaginário Potiguara, de maneira similar ao que diz Eliade (1992), a água representa 
fertilidade, renovação, renascimento, sendo "a sua fonte de criação uma vez que é gerado numa bolha de água, dentro de uma bolsa com líquido amniótico no ventre da mãe" (Barcellos, 2012, p. 123), ou ainda "[...] estar dentro da mata, ouvindo o murmúrio das águas, segundo a sabedoria indígena, há uma grande renovação espiritual em quem quer receber aquela energia vital" (Barcellos, 2012, p. 125). E assim, nascendo das águas e renascendo delas, sob o olhar antropológico, o mito se reafirma para além do tempo e do espaço geográfico em culturas distintas, porém ligadas por uma manifestação religiosa de pertencimento.

\section{Orar, rezar, benzer}

Na obra $O$ poder do mito, Campbell (1990) afirma que o mito é uma poética da vida, que nos faz viver cotidianamente, é o mesmo que estar vivo, ou seja, não se trata de buscar sentido na vida, mas ter sentido em viver. 0 autor ainda destaca que o mito tem $a$ priori quatro funções: mística - que é a admiração pelo misterioso, o espanto diante do mistério; a cosmológica - que diz respeito a forma de compreensão do mundo, que também é o objeto de estudo das ciências das religiões, dentre outras; a sociológica, que se apresenta como face de um determinado grupo social, e por fim, pedagógica, que é a orientação que segue o indivíduo e o seu grupo nas diversas etapas da sua existência. E segue afirmando que a mitologia é uma metáfora que perpassa a vida espiritual nas representações materiais.

Tem sido difícil viver na totalidade a espiritualidade indígena, principalmente no que diz respeito aos rituais das águas sagradas vividos nas cachoeiras, mangues e rios, locais sagrados para onde se dirigem quando necessitam invocar os espíritos, haja vista a presença do cristianismo que em muitos aspectos inibe as práticas rituais adquiridas com os mais velhos, embora estas ainda se conservem mais timidamente, e continuem sendo passadas de geração a geração, dos mais velhos para os mais novos.

Outro fator de influência é a forma agressiva como tem sido tratada o patrimônio material religioso Potiguara, vítima dos interesses econômicos de grupos industriais (Barcellos, 2012), porém é preciso persistir e não deixar morrer aquilo que causa pertencimento. Para cada mito, seu(s) rito(s). Assim:

Sendo o rito expressão e síntese do ethos cultural de um povo, portanto expressão de sua vida há de se salientar que, como ação, é vida acontecendo, processando-se, sendo significada, interpretada, ordenada, criada. 0 rito é vida criando vida, pois que no caos, na indeterminação, na falta de horizontes e sentido não sobrevivemos. É, portanto, atividade, trabalho, obra que opera, transforma, cria, significa (Vilhena, 2005, p. 21).

Para Vilhena (2005), em algumas tradições religiosas, a natureza e a sua espacialidade se apresentam de maneira ordenada, ou seja, tudo o que há na terra e a própria terra é criação de deus, deuses ou entidades. Aqui, remetemonos ao ritual do banhar-se nas águas, ou recolher-se nas cachoeiras. Beber dessa fonte vital é participar de uma convergência sagrada, que inicialmente, opera como fator de união que contribui para manter a etnicidade. Falar de mito sem associá-lo ao rito é como é tirar a energia vital dessa força significativa que responde pela dimensão sagrada, que se humaniza e materializa.

São muitos os ritos presentes na cultura Potiguara. Os que envolvem a água em muitos instantes mesclam o catolicismo trazido pelo colonizador, noutros os traços indígenas estão mais evidentes. Barcellos (2012) vai apontar que acerca da água, embora muito tenha a se relatar. Aqui foram evidenciados alguns rituais nos quais esse elemento fundamental para o povo Potiguara está presente. Há um rito de partilha entre os 
índios da aldeia de São Francisco, quando vão no carroção até o mangue. No trajeto trocam conversas entre eles, e na volta dividem o pescado com aquele que por alguma circunstância não tenha ido. Já nos rituais de sabedoria, comum em todas as aldeias, os banhos são utilizados para a purificação (banho de limpeza feito com ervas e plantas aromáticas) e para o "descarrego" (utilizando sete pedras de sal grosso e sete folhas de seis plantas diferentes). Já o Cacique Aníbal banha-se com a flor do manacá e vai para as matas e mangues se purificar.

Acerca dessas práticas, Barcellos (2012), continua relatando. Assim, outra prática comum, principalmente entre os mais velhos, é pedir a bênção dos encantados para adentrar no mar, no rio e no mangue. Além da presença da mãe d'água, que é uma jovem índia, tida como um espírito de luz, grande aliada da natureza. São rituais ligados a uma fonte que vivifica, protege, dinamiza a vida em sociedade, traz cura e renovo. Portanto, a água é enquanto elemento da natureza um dos pilares da cosmogonia indígena, que para o povo Potiguara, além de essencial alvo de respeito e culto.

\section{Considerações finais}

Longe de concluir, esse trabalho está muito mais para continuar, e é deixando claro que se torna necessário tecer algumas considerações ditas "à guisa de conclusão". Reconhecendo que muitas pesquisas ainda estão por vir, e também que muito ficou por dizer, que fique registrado, para além do profundo respeito às práticas aqui descritas da água, o que se pretende é que esse pequeno estudo seja um "mote" no qual se encontre um pretexto para outros textos e outras leituras.

Considerando a obra em questão, e todos os autores que gravitam em seu entorno, se trabalhou a importância da água como força Elemental, os mitos associados, reconhecidos como "mitos aquáticos" e os rituais praticados (aqueles revelados), ressaltando o mais profundo respeito com o qual nós indígenas a tratamos. Vivenciando $\mathrm{e}$ aprendendo, não podemos concluir, mas intuir. Não podemos tecer considerações finais, mas conseguimos mostrar parte do que se vive hoje no mundo das aldeias indígenas na no Estado da Paraíba.

Diante do exposto, é bem verdade que para além dos muros da academia há uma sabedoria muito peculiar e um modo característico de ver a vida, bem como expressar as religiosidades, e nessa linha compreende-se religiosidade como uma das manifestações da espiritualidade. E que não se despreze as ciências, mas torne-as instrumentos, ferramentas.

Assim, vamos considerar que a memória, a oralidade e a religiosidade deram voz aos mitos e ritos da espiritualidade Potiguara da Paraíba, e que o contexto histórico foi contemplado, uma vez que se buscou mostrar como são vivenciadas (os índios nas suas respectivas aldeias, e os desaldeados), mas que nos leva ao reconhecimento, como parte de um todo, dentro de um diálogo mantenedor de uma cultura muito própria, que durante alguns anos, séculos até, sobreviveu através da sabedoria dos mais velhos, que mantiveram-se fiéis aos espíritos dos encantados e perpetuaram as suas práticas religiosas.

Voltemos, pois, ao início. Não se pode falar da água e da sua importância para o indígena sem reconhecer a forte carga espiritual que ela carrega. Presente em todos os aspectos da vida indígena, e não é somente pela questão material que se manifesta a sua importância, mas sobretudo pela transcendência que dela advém. Não obstante a tudo que foi dito, ainda se faz necessário continuar a luta pela preservação da memória herdada pela ancestralidade, que é transmitida através da oralidade.

\section{Conflito de interesses}

Os autores declaram não haver conflitos de interesses. 


\section{Referências}

Barcellos, L. Práticas educativo-religiosas dos Potiguara da Paraíba. João Pessoa: Editora Universitária/UFPB, 2012.

Boff, L. Espiritualidade: um caminho de transformação. Rio de Janeiro: Sextante, 2006.

Campbell, J. 0 poder do mito. São Paulo: Palas Athena, 1990.

Eliade, M. Mito e realidade. São Paulo: Perspectiva, 1972.

Eliade, M. 0 sagrado e o profano. São Paulo: Martins Fontes, 1992.

Herckmans, E. Descripção geral da Capitania da Parahyba. Revista do Instituto Archeologico e Geographico Pernambucano, 1886. Disponível em: $<$ http://etnolinguistica.wdfiles.com/local-files/biblio:herckman-1886-parahyba/ herckman_1886_parahyba.pdf>. Acesso em: 29 nov. 2018.
Miranda e Silva, J. C. Traga-me um copo d'água, tenho sede: um estudo comparativo da qualidade da água dos Reservatórios de Marés e Gramame-Mamuaba, na Paraíba. João Pessoa: Universidade Federal da Paraíba, 2017. (Dissertação de mestrado).

Moura Filha, M. De Filipéia à Paraíba: uma cidade na estratégia de colonização do Brasil. João Pessoa: IPHAN, 2010.

Vilhena, M. A. Ritos: expressões e propriedades. São Paulo: Paulinas, 2005. 